\title{
Retinopathy of prematurity screening, stress related responses, the role of nesting
}

\author{
M Slevin, J F A Murphy, L Daly, M O’Keefe
}

\begin{abstract}
Aims/background-In a prospective study the degree of distress caused by retinopathy of prematurity (ROP) screening in a cohort of preterm infants was assessed and the modifying effects of nesting in reducing their discomfort was evaluated. Methods-38 preterm infants were included in the study. 19 infants were placed in a nest with boundaries (intervention group) and 19 infants were placed on a cot blanket (control group). Observations were made 2 minutes before, throughout, and 2 minutes after ROP examination. The factors observed were crying responses, neurobehavioural activity, and physiological changes (heart rate, oxygen saturation). Recordings were made using a video camera for crying and neurobehavioural activity and an Oxypleth monitor for heart rate and oxygen saturation. Results-During ROP screening, the total group of 38 infants (nested and nonnested combined) displayed increased neurobehavioural activity $(p<0.01)$ and crying $(p<0.01)$. The increased activity and crying coincided with the invasive part of the procedure. The distress caused by ROP screening was significantly less for the nested group compared with the non-nested group for both movement activity $(p<0.01)$ and crying $(p<0.01)$. The physiological data, heart rate, and oxygen saturation were not statistically significant.

Conclusion-ROP screening is distressing for preterm infants. Nesting can significantly reduce this discomfort. The findings in this study are of value in designing more optimal ROP examination schedules for infants.
\end{abstract}

(Br f Ophthalmol 1997;81:762-764)

Retinopathy of prematurity (ROP) is responsible for $40 \%$ of perinatally derived blindness. ${ }^{1}$ Screening for ROP became practicable in the 1970s with the advent of indirect ophthalmoscopy. ${ }^{2}$ An international classification for recording the retinal findings was a further significant advance. ${ }^{3}$ The need for early diagnosis of ROP became obligatory with the advent of successful treatment with cryotherapy. ${ }^{4}$ Subsequently, laser therapy ${ }^{5-8}$ has been shown to be as effective but with a further significant reduction in myopia. ${ }^{9}$ The 1995 working party report of the Royal College of Ophthalmologists and The British Association of Perinatal Medicine ${ }^{10}$ recommended that the early identification of ROP by screening should be standard practice. Consensus statements have also been issued by the American Academy of Pediatrics. ${ }^{11}$ Screening is now recommended for all infants of 31 weeks or less gestation or $1500 \mathrm{~g}$ or less birth weight. The first examination should be performed when the infant is 31 weeks' postmenstrual age.

ROP screening would appear to be both uncomfortable and painful for the preterm infant owing to the nature of the examination which involves the insertion of a speculum, use of an indentor, and a considerable amount of handling. To date, this discomfort and distress have not been widely appreciated. This study was mounted to evaluate the degree of disturbance caused by the procedure. In addition, we modified the technique by nesting half of the infants in an attempt to reduce the adverse effects of the examination.

\section{Patients and methods}

The study population was a cohort of 38 preterm infants, gestation $<32$ weeks, birth weight $<1500 \mathrm{~g}$, undergoing ROP screening. Parental consent was obtained. We divided the 38 infants into two groups, 19 infants in the nested (intervention) group, and 19 infants in the non-nested (control) group. The mean gestational age and birth weight for the nested and non-nested infants was 29.9 weeks, $1251 \mathrm{~g}$, and 28.8 weeks, $1149 \mathrm{~g}$ respectively. The infants were 31 weeks' postmenstrual age when screened.

Before screening, the nested infants were placed on a soft padded surface with boundaries that helped to maintain and support them in a flexed position but still facilitated unrestricted movement of their body and limbs. This nesting concept with Bendy Bunting was derived from Als et $a l^{12}$ developmental recommendations about the nursing care of preterm infants. The non-nested infants were placed on a standard cot blanket without any boundaries. None of the infants in the study was swaddled. Both groups of infants were thus able to move freely without any restriction.

The ophthalmic preparations for screening included the instillation of $2.5 \%$ phenylephrine and $0.5 \%$ cyclopentolate mydriatic eyedrops administered 60 and 30 minutes before the examination. Topical anaesthesia was not used as previous experience in our unit had not shown it to be of benefit (M O'K). An eyelid speculum was inserted and screening was conducted using an indirect ophthalmoscope with a 30 dioptre lens. Scleral indentation was not
Accepted for publication 28 May 1997 
Table 1 ROP screening, movement activity responses, nested and non-nested infants (median values)

\begin{tabular}{|c|c|c|c|c|c|c|c|c|c|}
\hline \multirow[b]{2}{*}{ Infants } & \multicolumn{3}{|c|}{ Before } & \multicolumn{3}{|c|}{ Procedure } & \multicolumn{3}{|c|}{ After } \\
\hline & $D$ & $P$ & $T$ & $D$ & $P$ & $T$ & $D$ & $P$ & $T$ \\
\hline Nested $(n=19)$ & 14 & 11 & 0 & 31 & 41.5 & 6.9 & 15 & 19 & 1 \\
\hline Non-nested $(n=19)$ & 37 & 47 & 8 & 41.5 & 61.1 & 15 & 30 & 43 & 2 \\
\hline
\end{tabular}

$\mathrm{D}=\operatorname{distal} ; \mathrm{P}=$ proximal $; \mathrm{T}=$ truncal.

Table 2 ROP screening, crying responses in nested and non-nested infants (median values)

\begin{tabular}{lll}
\hline Infants & $\begin{array}{l}\text { Time to cry onset } \\
\text { (seconds) }\end{array}$ & $\begin{array}{l}\text { Total duration of crying } \\
\text { (seconds) }\end{array}$ \\
\hline $\begin{array}{l}\text { Nested (n=19) } \\
\text { Non-nested }\end{array}$ & 61 & 11.8 \\
\hline
\end{tabular}

$\mathrm{p}<0.01$, comparing nested with non-nested infants.

required as funduscopy and peripheral visualisation were achieved by a combination of full pupillary dilatation and eyeball rotation using the doll's head reflex. All the infants were examined by the same consultant paediatric ophthalmologist.

The factors recorded were the infants' crying patterns, neurobehavioural activity, and physiological responses-namely, heart rate and oxygen saturation. A colour video camera with audiovisual facilities was used to record the infants' neurobehavioural activity and cry patterns. Heart rate and oxygen saturation concentrations were recorded with an Oxypleth monitor.

Recordings of all variables were made for 2 minutes before screening, throughout screening, and 2 minutes after screening. During video playback, using stop and freeze frame techniques, the infants' body movements were counted and analysed using a behavioural check sheet. ${ }^{9}$ For purposes of analysis, the infants' movements were divided into three categories: distal limb (hand, foot, digits), proximal limb (arm, leg), and truncal (trunk, head) movements. The results were expressed for each infant as the total number of movements per 2 minutes. Median values for the three epochs-before, during, and after screening were then calculated.

During video playback, the infants' cry patterns were observed. The two factors documented were time to onset of crying and the total duration of crying.

In the case of the physiological data, the median heart rate and oxygen saturation concentrations were calculated for the three epochs - before, during, and after screening.

The non-parametric sign test was used to compare the responses before and during the procedure for the total group of 38 infants. The Wilcoxon signed rank test was used to compare median values in the two groups of infants. A $1 \%$ and $5 \%$ two sided level of significance was calculated.

Results

The infants' activity increased during the screening procedure. For the total cohort of 38 infants (nested and non-nested combined), the distal limb $(\mathrm{p}<0.01)$, proximal limb $(\mathrm{p}<0.01)$, and truncal $(\mathrm{p}<0.01)$ movements were significantly greater during the examination. The responses coincided with the onset of eyelid speculum opening and quickly abated once the speculum was removed. Crying, which was one of the outcome variables, occurred only during the eye examination and ceased once it was completed.

When the nested and non-nested groups were compared (Table1), the movement responses were significantly different for all three epochs, 2 minutes before screening ( $p<0.01$ for distal, proximal, truncal movements), during screening $(\mathrm{p}<0.01$ for truncal movements), 2 minutes after screening $(\mathrm{p}<0.01$ for distal, proximal, truncal movements). Overall, there was less infant activity in the nested group.

Table 2 shows the crying response profiles for the nested and non-nested infants. These data showed that the non-nested infants started to cry earlier and that they cried for longer. The time to onset of crying in the nested and non-nested infants was 61 seconds and 11 seconds respectively. The total crying time was 11.8 seconds for the nested infants and 92.4 seconds for the non-nested group.

Individual infants showed tachycardia and oxygen desaturation but the median values did not demonstrate any significant differences for the procedure or between the nested and nonnested groups.

\section{Discussion}

Two findings emerge from this study. Firstly, ROP screening is distressing for preterm infants. Secondly, modification of the procedure with the use of nests can significantly reduce the infants' discomfort. The matter of pain and distress in relation to ROP examination is an important consideration in the newborn nursery as it is carried out on all infants of less than $1500 \mathrm{~g}$ and more than once for those with equivocal or abnormal findings. Large numbers are involved. In our own unit, 294 examinations were performed last year. Extrapolating from the annual birth rates, we would estimate that the numbers of infants of less than $1500 \mathrm{~g}$ having at least one ROP screening examination to be 500 in Ireland, 5000 in the UK, 30000 in the USA.

Brozanski ${ }^{14}$ at the 1993 International Conference on ROP stated that ROP examinations lasting longer than 2 minutes are not well tolerated by even the most stable infant. They appear to do best with a quick one person examination. Others ${ }^{15}{ }^{16}$ have expressed concern about the distress that the speculum may cause and suggest using a softer, more flexible device. Laws et al ${ }^{17}$ demonstrated an increase in heart rate of seven beats per minute and a $3 \%$ drop in oxygen saturation after the procedure but these changes in heart rate were not observed in those infants on methylxanthines. All the infants in our study were on theophylline medication, which may in part explain why there were no significant changes in heart rate during and after the procedure. Similarly, our oxygen saturation values did not show any alterations, but hypoxaemia would be unlikely because of the prompt administration 
of oxygen where necessary. Thus, we found that the physiological data were less informative than the neurobehavioural findings and crying patterns in pinpointing an infant's distress. This may be due to the fact that the neurobehavioural activity and crying responses seem to be more event oriented. We found that our infants settled as soon as the speculum was withdrawn. A recent review ${ }^{18}$ of 20 studies about pain, its assessment and management, revealed that physiological data were the main outcome variable in $50 \%$, crying time in $40 \%$, and behavioural responses in $20 \%$ of the papers. We combined all three methods in our study and would conclude that crying and behavioural responses work best when immediate assessments of pain and discomfort have to be made and acted upon. When babies are in pain, they express themselves both physically and verbally. The altered neurobehavioural and crying patterns observed in this study clearly illustrate this point. The changes in body and limb activity may be more important for the more preterm babies whose cry is weak and of low intensity.

There is increasing interest in the application of non-pharmacological measures in the alleviation of pain associated with invasive procedures in the newborn. ${ }^{19}{ }^{20}$ Interventions such as the promotion of physical containment during feeding and handling are measures now widely recommended to reduce stress responses in preterm infants. ${ }^{21}{ }^{22}$ Infants are now perceived as individuals and are no longer viewed as a homogeneous group. Babies respond differently to invasive procedures. One of the innovations of this individualised approach to care has been the recognition of the value of cot bedding and the provision of boundaries. These formed part of Als and colleagues' seminal study. ${ }^{12}$ This developmental concept has now become more formalised with the introduction of specific nesting items such as Bendy Bunting. ${ }^{22}$ Many neonatal units are incorporating these ideas into the nursing care protocols as it stabilises the infant before, during, and after a procedure. Infants who are nested tend to be calmer. ${ }^{23}$ This study showed the efficacy of nesting as a specific intervention in supporting infants during ROP screening. Nesting facilitates the integration and delivery of necessary medical procedures in a way that is developmentally appropriate and more empathetic for the infant. The infant's sense of security is increased and this in turn reduces energy expenditure. It is based on the principle that an optimal body posture-namely, flexion, which is the preferred position for the preterm infant, reduces autonomic instability. Anxiety heightens pain perception and responses to painful procedures. ${ }^{24}$ When individuals are reassured and properly settled, noxious stimuli can be beneficially modified at spinal cord level. The gate theory on the suppression of pain transmission ${ }^{25}$ may in part explain the value of nesting. In support of this we found that the nested infants were more stable in the period before the examination.
In summary we have observed that ROP screening can be distressing. We have demonstrated that nesting can significantly reduce that distress. These findings are of value in designing more optimal ROP examination schedules for preterm infants.

MS was in receipt of grants from the Health and Research Board and The Research College National Maternity Hospital.

1 Goggin M, O'Keefe M. Childhood blindness in the Republic of Ireland: a national survey. $\mathrm{Br} \quad \mathrm{f}$ Ophthalmol lic of Ireland:

2 Silverman WA. Retrolental fibroplasia: a modern parable. New York: Grune and Stratton, 1980.

3 Committee for the Classification of Retinopathy of Prematurity. An international classification of retinopathy of prematurity. Pediatrics 1984;74:127-33.

4 Cryotherapy for Retinopathy of Prematurity Cooperative Group. Multicentre trial of cryotherapy for retinopathy: one year outcome, structure and function. Arch Ophthalmol 1990;108:1408-16.

5 Goggin M, O'Keefe M. Diode laser for retinopathy of prematurity, early outcome. BrF Ophthalmol 1993;77:55962 .

6 Laser ROP Study Group. Laser therapy for retinopathy of prematurity. Arch Ophthalmol 1994;112:154-6.

7 O'Keefe M, Burke J, Algawi K, Goggin M. Diode laser photocoagulation to the vascular retina for progressively advancing retinopathy of prematurity. $\mathrm{Br} \mathcal{F}$ Ophthalmol 1995;79:1012-4.

8 Knight M, Nanan D, Algawi K, Bowell R, O'Keefe M. Advanced cicatrical retinopathy of prematurity-outcome and complications. Br F Ophthalmol 1996;80:343-5.

9 Knight-Nanan DM, O'Keefe M. Refractive outcome in eyes with retinopathy of prematurity treated with cryotherapy or diode laser: 3 year follow up. Br f Ophthalmol 1996;80:9981001

10 Retinopathy of prematurity: guidelines for screening and reatment. London: The Royal College of Ophthalmologists and The British Assocation of Perinatal Medicine Joint Working Party Report, 1995.

11 American Academy of Pediatrics and American College of Obstetricians and Gynecologists. Clinical considerations in the use of oxygen. In: Guidelines for perinatal care. 2nd ed. Elk Grove Village: March of Dimes, Birth Defects Foundation, 1988:244-8.

12 Als H, Lawhon G, Brown G, Gibes R, Duffy FH, McAulty $\mathrm{G}$, Blickman JG. Individualised behavioural and environmental care for the ELBW preterm infant at risk for bronchopulmonary dysplasia. Pediatrics 1986;78:1123-32.

13 Als H, Lawhon G, Duffy PH. Individualised developmental care for the very low birthweight preterm infant: medical care for the very low birthweight preterm infant: medic

14 Brozanski B. Risk of examination: the neonatologist's concern. In: Shapiro MJ, Biglan AW, Miller MT, eds. Proceedings of the international conference on retinopathy of prematurity, Chicago. Amsterdam, New York: Kugler, 1993: $7-8$.

15 Aronian D. Establishing an effective program for detection of retinopathy of prematurity and its natural history. In: Shapiro MJ, Biglan AW, Miller MT, eds. Proceedings of the international conference on retinopathy of prematurity. Amsterdam, New York: Kugler 199:23.

16 Hindle NW. An alternative method of screening for retinopathy of prematurity. In: Shapiro MJ, Biglan AW,
Miller MT, eds. Proceedings of the international conference on Miller MT, eds. Proceedings of the international conference on
retinopathy of prematurity. Amsterdam, New York: Kugler, retinopathy of

17 Laws DE, Morton C, Weindling M, Clark D. Systemic effects of screening for retinopathy of prematurity. $\mathrm{Br} \mathcal{F}$ Ophthalmol 1996;80:425-8.

18 Ulrich-Bucher H, Bucher-Schmid A. Treating pain in the neonate. In: Hansen TN, McIntosh N, eds. Current topics in neonatology. 1st ed. 1996:85-110.

19 Blass EM, Hofmeyer LB. Sucrose as an analgesic for newborn infants. Pediatrics 1991;87:215-8.

20 Rushfort JA, Levene MI. Effect of sucrose on crying in Rushfort JA, Levene Mis . Effect of sucrose on crying
response to heel stab. Arch Dis Child 1993;69:388-9.

21 Oehler JM. Developmental care of low birthweight infants. Nursing Clin N Am 1993;28:289-301.

22 Developmental care products. S Weymouth, USA: Developmental Care Division of Children's Medical Venture, 1993

23 Jorgensen KM. Developmental care of the premature infant: a course overview. S Weymouth, USA: Developmental Care Division of Children's Medical Ventures, 1993.

24 Brown AC. Pain and itch. In: Patton HD, Fuchs AF, Hille B, Scher AM, Steiner R, eds Textbook of physiology 1989;1: 346-64.

25 Melzak R, Wall PD. Pain mechanisms: a new theory. Science 1965;150:971-9. 